\title{
Relationships between social capital, patient empowerment, and self-management of patients undergoing hemodialysis: a cross-sectional study
}

\author{
Yongchao Hou' ${ }^{1}$ Li Li', Qian Zhou', Guohong Wang ${ }^{2}$ and Rongshan $\mathrm{Li}^{2 *}$
}

\begin{abstract}
Background: Hemodialysis is the most common treatment of end-stage renal disease. However, it is associated with a range of symptoms affecting patients' daily activities and quality of life. Effective self-management has proven crucial for the alleviation of symptoms. According to Social Cognitive Theory, social capital and patient empowerment may be important variables for predicting self-management. To date, few studies have explored the mechanisms underlying these results. The study aimed to verify whether patient empowerment mediated the effect of social capital on the self-management of hemodialysis patients.

Methods: The study was performed with 245 hemodialysis patients from January 2021 to April 2021 in Taiyuan, China. Demographic and clinical characteristics, social capital, patient empowerment, and self-management of patients undergoing hemodialysis were measured with a self-reported questionnaire. Descriptive statistics were used to summarize the participants' demographic and clinical characteristics, and bootstrapping tests were used to verify whether patient empowerment mediated the association of social capital with self-management in patients undergoing hemodialysis.
\end{abstract}

Results: Mediation analysis indicated that social capital and patient empowerment significantly predicted self-management. Patient empowerment partially mediated the relationship between social capital and self-management in hemodialysis patients.

Conclusions: The results suggest that hemodialysis patients show relatively poor self-management and that patient empowerment mediates both social capital and self-management. Strategies to mobilize patients' social networks and help them identify and utilize effective social resources may provide useful information regarding the implementation of optimal health management for their disease.

Keywords: End-stage renal disease, Hemodialysis, Mediation effect, Patient empowerment, Self-management, Social capital

*Correspondence: rongshanli13@163.com

2 Department of Nephrology, ShanXi Provincial People's Hospital, No. 29

Shuang Ta East Street, Taiyuan 030000, ShanXi, China

Full list of author information is available at the end of the article

\section{Background}

Chronic kidney disease, characterized by gradually declining kidney function [1], is increasingly becoming a global health issue. End-stage renal disease (ESRD) represents the advanced stage in which renal function progresses to a state of failure. Renal transplantation 
is the preferred treatment for ESRD [2]. However, this treatment is not always feasible due to limited numbers of donors, lack of appropriate medical facilities, or the ineligibility of recipients for transplantation [3-6]. Therefore, hemodialysis (HD) has become the most common treatment to prolong the survival of patients. According to statistics, approximately $90 \%$ and $86 \%$ of the dialysis population are undergoing HD in the USA and China, respectively $[7,8]$. Although $\mathrm{HD}$ is lifesaving, patients on HD endure a range of symptoms, such as fatigue, pain, sleep disturbance, itching, anorexia, vomiting, nausea, constipation, anxiety, and depression [9-11], affecting their daily activities, well-being, and quality of life [1114]. In order to alleviate these symptoms, HD patients are required to follow a unique and restrictive treatment regimen, including regular attendance at a dialysis unit for treatment, monitoring of diet and fluid intake, and medication restriction [15]. These lifestyle changes require a considerable degree of self-management [16].

Self-management is defined as the ability of a given patient to manage the illness, change lifestyle, and thereby live with a chronic illness [17]. The self-care compliance of hemodialysis patients has a direct influence on their health status and quality of life [18]. Selfmanagement levels, especially during the interdialysis period, are strongly related to patient outcomes $[19,20]$, and also determine the treatment methods and ultrafiltration quantity during subsequent dialysis procedures [21]. However, self-management levels at present have been shown to be suboptimal in hemodialysis patients, particularly in low- and middle-income countries such as China $[15,22]$. A deeper understanding of factors associated with self-management is warranted [23]. Accordingly, this study was conducted to explore one potential mechanism of self-management, thereby providing useful knowledge for implementing targeted strategies to enhance self-management in patients with HD.

Social capital broadly refers to the relationships, social networks, support systems, and resources to which a given individual has access [24] and is composed of bonding social capital and bridging social capital. Bonding social capital refers to the emotional or substantive support-based resources between strongly tied persons (e.g., family and closest friends), whereas bridging social capital concerns the information-based benefits between weakly tied persons in heterogeneous networks (e.g., colleagues, acquaintances, and friends in general) $[25,26]$. The importance of social capital as a determinant of health outcomes has been a topic of increasing research interest in recent years. From an interpersonal perspective, social capital can create a supportive environment that enables patients to take a more active role in their care management
[27]. For example, studies have documented that social capital can facilitate improved self-management among patients with type 2 diabetes and HIV [28, 29]. Social capital was also positively correlated with the adherence to treatment or management plans in individuals with chronic diseases [30, 31]. In a qualitative study performed on hemodialysis patients, social capital was proposed to be conducive to their medication management [32]. However, few quantitative studies have reported the relationship between social capital and self-management in hemodialysis patients, especially in the context of Chinese culture. Thus, we hypothesized that social capital might exert a direct positive effect on self-management in patients undergoing HD in China.

A better understanding of how social capital impacts on self-management of HD patients is necessary. Social Cognitive Theory [33] indicates that individual behavior does not simply respond to, nor is solely influenced by the external environment. Instead, it is mediated to a large extent by cognition, and the behavior of an individual is the outcome of bidirectional interactions between personal, environmental, and behavioral factors. As a previous study suggested, self-concept, as the core of the self-cognition system, is affected by the external environment of parental rearing styles. Furthermore, it has subjective initiative, and together with external environment, affects middle school students' learning burnout (behavioral outcomes) [34]. In the present study, patient empowerment was seen as a critical aspect of the self-cognition system, and we proposed that patient empowerment was likely to be a mediator of social capital (external environment) and self-management (behavioral outcomes). Patient empowerment in a healthcare context refers to the degree to which patients are able to act autonomously and think critically concerning their own treatment and care [35]. The concept of patient empowerment emphasizes the patient-centeredness of health care, stressing that the patient has the right to choose their treatment instead of simply complying with the offered treatments. In the empowerment process, healthcare providers offer accurate and comprehensible information and patients can access and screen multiple information to help them identify their strengths, thereby allowing them to determine and manage their disease [36]. Prior studies have confirmed that social capital is correlated with patient empowerment and that individuals with greater social capital are more likely to perceive themselves as empowered [27]. However, there appear to be no studies on the relationship between social capital and patient empowerment in HD patients. Therefore, we hypothesized that social capital was likely to be positively associated with patient empowerment in HD patients. 
Additionally, patient empowerment has been shown to be associated with better health outcomes [37]. It has been suggested that patients with higher health literacy, empowerment predisposes them to better health management [38]. Empowerment is an important psychological factor and has been found to play a positive role in various health fields. A body of empirical literature on diabetes patients has suggested that empowerment can substantially alter their self-care behaviors [39-41]. Along the same lines, empowerment was found to actively impact on the self-management practices of asthma patients [42]. To sum up, there is evidence that patient empowerment is related to the self-management of several chronic diseases. We thus hypothesized that patient empowerment may be an important predictor of self-management in patients receiving HD.

Based on the above theory and literature, we conducted a survey of HD patients, with the aim of quantifying HD patients' self-management and identifying the underlying factors contributing to self-management. We first hypothesized that there was an association between social capital and self-management. Moreover, we speculated that this relationship was mediated by patient empowerment. To our knowledge, the relationships among these variables have not been investigated in patients receiving HD in China.

\section{Methods}

\section{Study design}

This was a cross-sectional study, aiming to interpret the correlations between social capital, patient empowerment, and self-management, to identify the underlying path of social capital to self-management in patients receiving $\mathrm{HD}$, and to verify whether patient empowerment acts as a mediator between social capital and selfmanagement in patients receiving HD.

\section{Setting and participants}

The study participants were recruited from two dialysis units at tertiary Level-A hospitals located in Taiyuan, China using a convenience sampling approach from January 2021 - April 2021. The sample size was predetermined on the basis of Kendall's principle that the sample size should be 5-10 times the number of variables [43]. As this study included a total of 17 variables, including demographic/clinical variables, the estimated minimum sample size was 85 . Allowing a $20 \%$ loss to follow-up, 258 patients were thus enrolled in the study. The inclusion criteria were patients who: (1) had undergone routine hemodialysis for at least three months; (2) were 18 years of age or older. The exclusion criteria were patients who: (1) exhibited hearing impairments; (2) were unable to communicate in Chinese; (3) suffered from psychological or cognitive disorders; (4) had physical limitations associated with their self-care; (5) were without arteriovenous fistulae, as the items of $5,9,15$ in the self-management scale for hemodialysis patients are related to arteriovenous fistulae, such as item 5 "taking care of arteriovenous fistula". Nine participants refused to cooperate during the investigation, three participants were unable to continue to attend the survey due to deterioration of illness, and one suffered from mild depression. Therefore, the final sample included 245 patients (participation rate $=94.96 \%$ ).

\section{Procedure}

The entire survey was conducted by three trained surveyors who only knew the items of the questionnaire instead of the purpose and process of the research. The surveyors firstly met with the potential participants and discussed the study goals, background, significance, and confidentiality. After signing an informed consent document, the participants filled in the self-reported questionnaire, specifically, questions on demographic and clinical characteristics, social capital, patient empowerment, and selfmanagement according to their own situation. If patients were unable to accurately understand an item in the questionnaire, the surveyors provided explanations and instructions. The surveyors also assisted patients with difficulty with their hands in filling in the questionnaires. In both cases, the surveyors strictly followed the participants' wishes without induced descriptions. Finally, they carefully evaluated each questionnaire to ensure that it had been fully completed. The Ethics Committee of Provincial People's Hospital approved this study (Approval No. [2021]48), and all protocols were consistent with the 1964 Helsinki Declaration and its later amendments or comparable ethical standards.

\section{Study instrument Personal characteristics}

The patients' demographic/clinical variables regarding age, sex, educational level, duration of dialysis, and comorbidities were collected.

\section{Social capital}

The social capital of HD patients was measured using the Chinese revised version of the Social Capital Scale, which was originally developed by Williams [44] and applied to Chinese patients in 2019 [27]. The scale was used to assess both online and offline social capital. The present study adopted offline settings of the scale to assess the social capital of HD patients. The Chinese revised version of the scale contains 15 items and 2 subscales: bonding social capital and bridging social capital. All items in the scale are rated on a 5-point scale from 1 (strongly 
disagree) to 5 (strongly agree). The overall scores are calculated by adding all individual scores together, with higher scores corresponding to more social capital. It has good psychological measurement characteristics [27]. In our study, the Cronbach's $\alpha$ for this total scale was 0.897 and confirmatory factor analysis showed that the structure for the scale was stable.

\section{Patient empowerment}

In order to assess perceptions of patient empowerment in individuals receiving HD, we adopted the Chinese version of the Client Empowerment Scale [36], which was originally developed by Mikky [45]. The Chinese version of the scale contains 44 items and 6 dimensions: informed confidence, client-provider relationship, social advocacy, awareness, control, and client-client support. The items are scored on a 5-point scale from 1 (strongly disagree) to 5 (strongly agree), with the overall scores being the sum of the individual scores. Higher scores correspond to greater levels of empowerment. This scale has been widely used among patients with chronic diseases and has been proven to have good psychological properties [36]. In this study, the Cronbach's $\alpha$ was 0.926 .

\section{Self-management}

Self-management in the study subjects was assessed with the self-management scale for hemodialysis patients [46], adopting the Chinese version of this scale for the present analyses [15]. This scale is composed of 20 items and 4 subscales: partnership, problem-solving, self-care, and emotional management. The patients were instructed to respond to each item on a 4-point Likert scale ranging from 1 (never) to 4 (always), with the total score being used to assess the overall self-management capacity of a given patient. Higher scores indicated higher levels of self-management. The Chinese version of this scale has been demonstrated to exhibit good reliability and validity when used to assess Chinese HD patients [15]. The Cronbach's $\alpha$ of the total scale in this study was 0.866 .

\section{Data analysis}

The independent-samples t-test or the one-way ANOVA was used to analyze the distribution of self-management based on different demographic/clinical characteristics when the data were normally distributed and showed homogeneity of variance. The normality of the data distribution was determined using the Kolmogorov-Smirnov test, and normally distributed data were reported as means and standard deviations. The main variables in this study tested by Kolmogorov-Smirnov conformed to normality (social capital, $p=0.062$; patient empowerment, $p=0.079$; self-management, $p=0.200$ ). Pearson correlation coefficients were then used to assess the associations between social capital, patient empowerment, and self-management. The mediating analysis was finally performed with PROCESS macro in SPSS [47]. The age and educational level which were associated with self-management of hemodialysis patients in the results of the previous studies were ranked as covariate variables in this study $[16,48]$. Therefore, we put the age, educational level into the 'covariates' to control, self-management was the dependent variable, social capital was the independent variable and patient empowerment was the mediating variable when conducting the bootstrap process. The mediation effect was tested by the bootstrap resampling method, and 5000 bootstraps and 95\% confidence intervals (CIs) were used to assess the mediation effect with PROCESS v3.3 (by Andrew F. Hayes) of SPSS 23.0. The $95 \%$ confidence intervals of the indirect effect did not contain zero and the mediating effect was statistically significant. Two-tailed $\mathrm{p}$-values $<0.05$ indicated statistical significance.

\section{Results \\ Differences in self-management based on participant demographic/clinical characteristics}

The associations between participant demographic/clinical characteristics and self-management scores were outlined in Table 1. As shown in Table 1, most participants were 60 years or older (37.1\%). Most participants were men $(60.8 \%)$, had received middle school education or less $(40.0 \%)$, had received regular dialysis for $1-4$ years (42.0\%), and accompanied with comorbidities (84.5\%). Considering the demographic and clinical characteristics, the self-management scores differed significantly according to age $(F=5.774, p<0.001)$ and educational level $(F=10.008, p<0.001)$. The overall trend was that younger and more highly educated participants had higher levels of self-management.

\section{Correlations between social capital, patient empowerment, and self-management}

As shown in Table 2, positive correlations between social capital $(r=0.394)$, patient empowerment $(r=0.608)$ and self-management were observed, with an additional positive correlation seen between social capital and patient empowerment $(r=0.478)$.

\section{Mediation effect of patient empowerment on the relationship between social capital and self-management}

The mediation effect results were shown in Tables 3 and 4 . The results showed that the total effect (path c) of social capital on self-management was 0.355 ( $p<0.001)$. The coefficients of path a $(B=0.785, p<0.001$, $95 \%$ CI $[0.585,0.985])$ and path $\mathrm{b}(B=0.278, \mathrm{p}<0.001$, 
Table 1 Association between participant characteristics and self-management scores $(N=245)$

\begin{tabular}{|c|c|c|c|c|}
\hline Variable & $N(\%)$ & $M(S D)$ & $F(t)$ & $P$ \\
\hline \multicolumn{5}{|l|}{ Age (years) } \\
\hline$<30$ & $24(9.8)$ & $55.63(11.23)$ & \multirow[t]{5}{*}{$F=5.774$} & \multirow[t]{5}{*}{$<.001$} \\
\hline $30-39$ & $49(20.0)$ & $58.80(11.83)$ & & \\
\hline $40-49$ & $36(14.7)$ & $56.36(10.62)$ & & \\
\hline $50-59$ & $45(18.4)$ & $51.11(9.67)$ & & \\
\hline$\geq 60$ & $91(37.1)$ & $50.73(10.86)$ & & \\
\hline \multicolumn{5}{|l|}{ Sex } \\
\hline Male & $149(60.8)$ & $53.87(10.71)$ & \multirow{2}{*}{$\mathrm{t}=.259$} & \multirow[t]{2}{*}{.796} \\
\hline Female & $96(39.2)$ & $53.48(12.15)$ & & \\
\hline \multicolumn{5}{|l|}{ Educational level } \\
\hline Middle school or less diploma & $98(40.0)$ & $50.19(10.68)$ & \multirow[t]{3}{*}{$F=10.008$} & \multirow[t]{3}{*}{$<.001$} \\
\hline $\begin{array}{l}\text { High school diploma or graduate equivalency } \\
\text { diploma }\end{array}$ & $69(28.2)$ & $54.45(10.21)$ & & \\
\hline College school or higher diploma & $78(31.8)$ & $57.50(11.69)$ & & \\
\hline \multicolumn{5}{|l|}{ Duration of dialysis (years) } \\
\hline$<1$ & $101(41.2)$ & $54.47(12.28)$ & \multirow[t]{4}{*}{$\mathrm{F}=.484$} & \multirow[t]{4}{*}{.694} \\
\hline $1-4$ & $103(42.0)$ & $53.65(10.21)$ & & \\
\hline $5-9$ & $31(12.7)$ & $52.39(11.18)$ & & \\
\hline$\geq 10$ & $10(4.1)$ & $51.00(12.28)$ & & \\
\hline \multicolumn{5}{|l|}{ Comorbidities } \\
\hline Yes & $207(84.5)$ & $53.46(11.24)$ & \multirow[t]{2}{*}{$\mathrm{t}=-.840$} & \multirow[t]{2}{*}{.402} \\
\hline No & $38(15.5)$ & $55.13(11.51)$ & & \\
\hline
\end{tabular}

$M$, mean score $S D$, standard deviation. Comorbidities refer to those diseases that accompany with ESRD and that can reduce the survival rates and quality of life of patients $[15,16]$

Table 2 Distributions and correlations among the main study variables $(N=245)$

\begin{tabular}{lllll}
\hline Variable & $\boldsymbol{M}(\boldsymbol{S D})$ & $\mathbf{1}$ & $\mathbf{2}$ & $\mathbf{3}$ \\
\hline 1 Social capital & $52.98(11.04)$ & 1 & & \\
2 Patient empowerment & $158.63(20.23)$ & $.478(<.01)$ & 1 & \\
3 Self-management & $53.72(11.28)$ & $.394(<.01)$ & $.608(<.01)$ & 1 \\
\hline
\end{tabular}

$M$, mean score $S D$, standard deviation
95\% CI [0.213, 0.343]) were significant, indicating that social capital was positively correlated with patient empowerment and patient empowerment was positively correlated with self-management. In addition, the indirect effect $(a * b)$ between social capital and self-management via patient empowerment was 0.218 (95\% CI $[0.115,0.335])$. Therefore, the mediation effect accounted for $61.41 \%$ of the total effect of social capital

Table 3 The unstandardized regression coefficients $(B)$ with Standard Errors (SE) and 95\% confidence intervals (CI) estimating patient empowerment and self-management

\begin{tabular}{|c|c|c|c|c|c|c|}
\hline & \multicolumn{3}{|c|}{ Patient empowerment } & \multicolumn{3}{|c|}{ Self-management } \\
\hline & B & $S E$ & $95 \% \mathrm{Cl}$ & $B$ & $S E$ & $95 \% \mathrm{Cl}$ \\
\hline Constant & 133.439 & 7.006 & {$[119.639,147.239]$} & 7.452 & 5.691 & {$[-3.759,18.664]$} \\
\hline Age & -2.098 & 0.806 & {$[-3.686,-0.511]$} & -0.968 & 0.420 & {$[-1.794,-0.141]$} \\
\hline Educational level & -4.315 & 1.373 & {$[-7.020,-1.610]$} & -0.785 & 0.719 & {$[-2.202,0.632]$} \\
\hline Social capital & 0.785 & 0.102 & {$[0.585,0.985]$} & 0.137 & 0.058 & {$[0.023,0.252]$} \\
\hline Patient empowerment & & & & 0.278 & 0.033 & {$[0.213,0.343]$} \\
\hline$R^{2}$ & 0.294 & & & 0.403 & & \\
\hline F & 33.381 & & & 40.545 & & \\
\hline$p$ & $<.001$ & & & $<.001$ & & \\
\hline
\end{tabular}

Effects are significant when the upper and lower bound of the $95 \%$ confidence intervals $(\mathrm{Cl})$ does not contain zero 
Table 4 Summary of effects of mediation

\begin{tabular}{llllll}
\hline Mediation & Effect $(\boldsymbol{B})$ & Boot SE & Boot LLCl & Boot ULCl & $\begin{array}{l}\text { Relative } \\
\text { effect } \\
(\%)\end{array}$ \\
\hline Path ab & .218 & .057 & .115 & .335 & $61.41 \%$ \\
Path c' & .137 & .058 & .019 & .023 & $38.59 \%$ \\
Path c & .355 & .059 & .239 & .472 & \\
\hline
\end{tabular}

Note: Path ab, indirect effect of social capital on self-management; Path $c^{\prime}$, direct effect of social capital on self-management; Path $c$, total effect of social capital on self-management; Effect( $B)$, unstandardized coefficient BootSE, standard error estimated using bootstrapping method Boot $L L C l$, lower level of confidence interval estimated using bootstrapping method BootULCI, upper level of confidence interval estimated using bootstrapping method; Relative effect refers to the indirect effect accounts for $61.41 \%$ of the total effect, and the direct effect accounts for $38.59 \%$ of the total effect, respectively

and self-management. The direct effect of social capital on self-management was $0.137(p<0.05,95 \%$ CI [0.023, $0.252]$ ), indicating that patient empowerment partially mediated the association between social capital and selfmanagement. The final mediation model was shown in Fig. 1.

\section{Discussion}

Previous studies pointed out that self-management in HD patients was suboptimal, indicating a need for improvement [15, 22]. One of the important goals in HD treatment is the self-management of routine activities, and good self-management results improve both the individual's well-being and health [49]. Besides, according to Social Cognitive Theory, social capital and patient empowerment were probably regarded as the critical factors affecting self-management in HD patients. Addressing these issues has been an essential part of patient care. To our knowledge, the associations between social capital, patient empowerment, and selfmanagement have not been elucidated in a mediation model. The present study confirmed our earlier hypothesis, that is, social capital and patient empowerment were positively related to self-management in HD patients, and patient empowerment was found to play a mediating role between social capital and self-management, which provided an empirical reference for promoting the selfmanagement of HD patients based on Social Cognitive Theory.

We found that the participants with greater social capital had higher levels of self-management, which mirrors the research conducted by Koetsenruijter et al. [50] suggesting that self-care was associated with the patient's social organization, community, and information and emotional network. In addition, social capital has been found to be beneficial for the maintenance of a healthy lifestyle in patients with coronary heart disease [51]. In terms of cultural differences, family and kinship are highly valued in China compared with western countries, and patients suffering from poor health and economic hardship are relatively vulnerable and prefer to obtain support from their families. Under these conditions, the mobilization of the patient's social networks and obtaining the material and spiritual support is quite essential and even meaningful. Nevertheless, it is noteworthy that these studies have adopted different social capital instruments to validate the relationship between social capital and self-management in different cultural contexts.
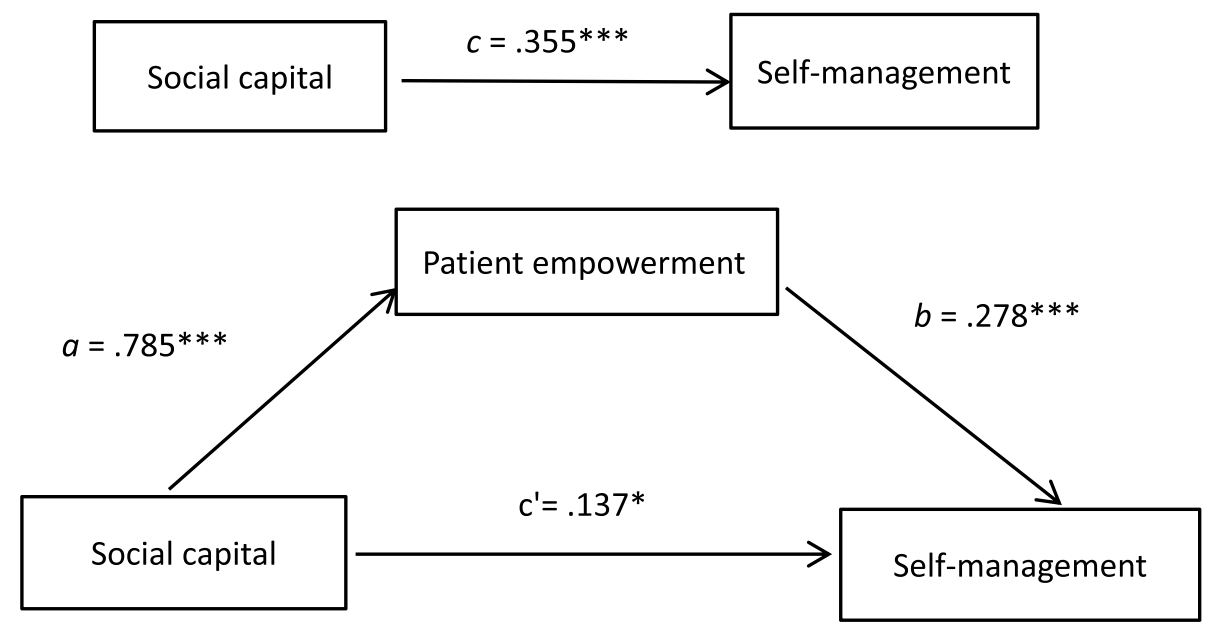

Fig. 1 Mediation effect of patient empowerment between social capital and self-management. Path c indicates total effect of social capital on self-management, Path $a * b$ indicates indirect effect of social capital on self-management via patient empowerment, Path $c^{\prime}$ indicates direct effect of social capital on self-management without patient empowerment. ${ }^{*} p<.05,{ }^{* *} p<.01$, ${ }^{* *} p<.001$ 
Our results showed a significant correlation between patient empowerment and social capital. Social capital affords individuals with chronic health issues more emotional and informational support, thereby improving their feelings of empowerment [52]. In addition, our study indicated that patient empowerment was positively associated with self-management. This is consistent with a previous study [42]. Patients who rate themselves positively are more capable of self-management. In contrast, individuals in some cases possess sufficient resources to move to a more healthy state [53], but could not effectively utilize these resources such that their health condition is perceived to be unmanageable. Healthcare professionals can thus help guide patients in a better way to access support from patient organizations and their families [54], thus leading to a better self-management behaviour.

As described earlier, patient empowerment partially mediated the association of social capital with self-management. The effect of social capital on selfmanagement can be partly explained by patient empowerment. As we know, social capital can provide a stable social environment for accessing emotional support and health information. Bonding social capital including a closer connection with family members, relatives, and friends can help HD patients regain confidence during their illness, while bridging social capital indicating a larger social network provided by physicians, health organizations, and patients with the same disease can help them access useful information for their health. The specific forms of social capital serve as a supportive environment to empower patients by providing useful advice and tangible assistance that are conducive to the patients' self-management skills and confidence, promoting improvement in the patients' self-management behaviors [27].

Despite these encouraging results, there are some limitations to the study that need to be noted. First and foremost, a convenience sample of eligible participants was conducted, which may have led to a risk of bias and poor representation of the total population, thus limiting generalizability to other populations. Moreover, we only discussed the total scores of the three main variables and their relationships, and the relationships between the dimensions of each scale were not considered. Therefore, future studies should analyze the dimensions of each scale to make the results more comprehensive. Furthermore, the study only regarded demographic and clinical variables as control variables, other psychosocial variables that may also influence self-management. It is suggested to include as many control variables affecting self-management as possible to make the results more accurate. Finally, all data were collected through selfreports and were thus susceptible to bias, and subjective and objective evaluation criteria are considered more beneficial.

\section{Conclusions}

This study extends our current knowledge of the selfmanagement of HD patients by elucidating its underlying mechanisms based on Social Cognitive Theory. The findings suggest that strengthening patient empowerment is beneficial for improving self-management in relation to the social environments of HD patients. In addition, it is recommended that both social relations and decision empowerment should be taken into account in the treatment regimens of HD patients.

\section{Abbreviations}

ESRD: End-stage renal disease; HD: Hemodialysis; M: Mean score; SD: Standard deviation; SE: Standard error; LLCl: Lower limit of 95\% confidence interval; ULCl: Upper limit of $95 \%$ confidence interval.

\section{Acknowledgements}

We are grateful to the leaders of Renal Transplantation and Dialysis Center of ShanXi Second People's Hospital for their support. In addition, we thank all the participants of the study and all the authors of the questionnaires used in this study for their support in making this study possible.

\section{Authors' contributions}

YCH worked on study design and conception, wrote the first draft of the manuscript. LL participated in the writing and critically improvement of the manuscript. QZ and GHW participated in surveying and data analysis. RSL the project coordinator and participated in all parts of the work. All authors provided critical revision of the paper and read and approved the final version submitted.

\section{Funding}

This research did not receive any specific grant from funding agencies in the public, commercial, or not-for-profit sectors.

Availability of data and materials

The datasets used in the study are available from the corresponding author on reasonable request.

\section{Declarations}

Ethics approval and consent to participate

This study received the approval from the Ethics Committee of Provincial People's Hospital (Approval No. [2021]48). All participants in this research gave written informed consent before the study conducted.

\section{Consent for publication}

Not applicable

\section{Competing interests}

The authors declare that they have no competing interests.

\section{Author details}

${ }^{1}$ Emergency Department, ShanXi Provincial People's Hospital, No. 29 Shuang Ta East Street, Taiyuan 030000, ShanXi, China. ${ }^{2}$ Department of Nephrology, ShanXi Provincial People's Hospital, No. 29 Shuang Ta East Street, Taiyuan 030000, ShanXi, China.

Received: 22 September 2021 Accepted: 7 January 2022 Published online: 21 February 2022 


\section{References}

1. The National Kidney Foundation: Global Facts: About Kidney Disease. https://www.kidney.org/kidneydisease/global-facts-aboutkidney-disease. Accessed 8 Mar 2018.

2. Landreneau K, Lee K, Landreneau MD. Quality of life in patients undergoing hemodialysis and renal transplantation-a meta-analytic review. Nephrol Nurs J. 2010;37(1):37-44.

3. Patel SR, Chadha P, Papalois V. Expanding the live kidney donor pool: ethical considerations regarding altruistic donors, paired and pooled programs. Exp Clin Transplant. 2011;9(3):181-6.

4. Saidi RF, Kenari SH. Challenges of organ shortage for transplantation: solutions and opportunities. Int J Organ Transplant Med. 2014;5(3):87-96.

5. Abecassis M, Bartlett ST, Collins AJ, Davis CL, Delmonico FL, Friedewald JJ, et al. Kidney transplantation as primary therapy for end-stage renal disease: a National Kidney Foundation/Kidney disease outcomes quality initiative (NKF/KDOQI ${ }^{\mathrm{TM}}$ ) conference. Clin J Am Soc Nephrol. 2008;3(2):471-80. https://doi.org/10.2215/CJN.05021107.

6. Patient education: Dialysis or kidney transplantation — which is right for me? (Beyond the Basics). https://www.uptodate.com/contents/dialy sis-or-kidney-transplantation-which-is-right-forme-beyond-the-basics. Accessed 9 Mar 2018.

7. Saran R, Robinson B, Abbott KC, Agodoa LYC, Ayanian J, Bragg-Gresham J, et al. US Renal Data System 2016 Annual Data Report: epidemiology of kidney disease in the United States. Am J Kidney Dis. 2017;69(3)(suppl 1):S1-S688. https://doi.org/10.1053/j.ajkd.2016.12.004.

8. Li PK, Lui SL, Ng JK, Cai GY, Chan CT, Chen HC, et al. Addressing the burden of dialysis around the world: A summary of the roundtable discussion on dialysis economics at the First International Congress of Chinese Nephrologists 2015. Nephrology (Carlton). 2017;22(Suppl 4):3-8. https:// doi.org/10.1016/j.ijnurstu.2017.06.008.

9. Murtagh FE, Addington-Hall J, Higginson IJ. The prevalence of symptoms in end-stage renal disease: a systematic review. Adv Chronic Kidney Dis. 2007;14(1):82-99. https://doi.org/10.1053/j.ackd.2006.10.001.

10. AlDukhayel A. 2015. Prevalence of depressive symptoms among hemodialysis and peritoneal dialysis patients. Int J Health Sci. 9(1):9-16. https:// doi.org/10.12816/0024678.

11. Almutary $\mathrm{H}$, Bonner $\mathrm{A}$, Douglas $\mathrm{C}$. Which patients with chronic kidney disease have the greatest symptom burden? A comparative study of advanced CKD stage and dialysis modality. J Ren Care. 2016;42(2):73-82. https://doi.org/10.1111/jorc.12152.

12. Janssen DJ, Almutary H, Bonner A, Douglas C. Which patients with chronic kidney disease have the greatest symptom burden? A comparative study of advanced CKD stage and dialysis modality. J Ren Care. 2016;42(2):73-82. https://doi.org/10.1111/jorc.12152.

13. Caplin B, Kumar S, Davenport A. Patients' perspective of haemodialysis associated symptoms. Nephrol Dial Transplant. 2011;26(8):2656-63. https://doi.org/10.1093/ndt/gfq7634.

14. Flythe JE, Dorough A, Narendra JH, Forfang D, Hartwell L, Abdel-Rahman E. Perspectives on symptom experiences and symptom reporting among individuals on hemodialysis. Nephrol Dial Transplant. 2018;33(10):184252. https://doi.org/10.1093/ndt/gfy069.

15. Li H, Jiang YF, Lin CC. Factors associated with self-management by people undergoing hemodialysis: a descriptive study. Int J Nurs Stud. 2014;51(2):208-16. https://doi.org/10.1016/j.jjnurstu.2013.05.012.

16. Gela D, Mengistu D. Self-management and associated factors among patients with end-stage renal disease undergoing hemodialysis at health facilities in Addis Ababa. Ethiopia Int J Nephrol Renovasc Dis. 2018;11:329-36. https://doi.org/10.2147/ijnrd.S184671.

17. Barlow J, Wright C, Sheasby J, Turner A, Hainsworth J. Self-management approaches for people with chronic conditions: a review. Patient Educ Couns. 2002;48(2):177-87. https://doi.org/10.1016/s0738-3991(02) 00032-0.

18. Suh SR, Cho IH. Influence of hemodialysis patient's stress and acceptance on their psychosocial adaptation and quality of life. J Korea Contents Assoc. 2014;14(11):829-37. https://doi.org/10.5392/JKCA.2014.14.11.829.

19. Shirazian S, Crnosija N, Weinger K, Jacobson AM, Park J, Tanenbaum ML, Hammock AC. 2016 The self-management experience of patients with type 2 diabetes and chronic kidney disease: A qualitative study. Chronic ||ln. 12(1):18-28. https://doi.org/10.1177/1742395315614381.

20. Song MK, Ward SE, Hladik GA, Bridgman JC, Gilet CA. Depressive symptom severity, contributing factors, and self-management among chronic dialysis patients. Hemodial Int. 2016;20(2):286-92. https://doi.org/10. 1111/hdi.12317.

21. Ong SW, Jassal SV, Porter E, Logan AG, Miller JA. Using an electronic selfmanagement tool to support patients with chronic kidney disease (CKD): a CKD clinic self-care model. Semin Dial. 2013;26(2):195-202. https://doi. org/10.1111/sdi.12054.

22. Tao $X$, Chow SK, Wong FK. A nurse-led case management program on home exercise training for hemodialysis patients: A randomized controlled trial. Int J Nurs Stud. 2015;52(6):1029-41. https://doi.org/10.1016/j. ijnurstu.2015.03.013.

23. Washington T, Zimmerman S, Browne T. Factors Associated with Chronic Kidney Disease Self-Management. Soc Work Public Health. 2016;31(2):5869. https://doi.org/10.1080/19371918.2015.1087908.

24. Salehi A, Harris N, Coyne E, Sebar B. Perceived control and self-efficacy, subjective well-being and lifestyle behaviours in young Iranian women. J Health Psychol. 2016;21(7):1415-25. https://doi.org/10.1177/1359105314554818.

25. Putnam RD. Bowling alone: The collapse and revival of American community. New York: Simon and Schuster; 2000.

26. Vitak J, Ellison NB. There's a network out there you might as well tap': Exploring the benefits of and barriers to exchanging informational and support-based resources on Facebook. New Media Soc. 2013;15(2):24359. https://doi.org/10.1177/1461444812451566.

27. Jiang S, Street RL. The effects of patient-centered communication, social capital, and internet use on patient empowerment: a cross-sectional study in China. Glob Health Promot. 2019;26(4):33-43. https://doi.org/10. 1177/1757975917749197.

28. Vissenberg C, Nierkens V, van Valkengoed I, Nijpels G, Uitewaal P, Middelkoop B, Stronks K. The impact of a social network based intervention on self-management behaviours among patients with type 2 diabetes living in socioeconomically deprived neighbourhoods: a mixed methods approach. Scand J Public Health. 2017:45(6):569-83. https://doi.org/10. 1177/1403494817701565

29. Webel AR, Smith C, Perazzo J, Phillips JC, Al Battashi H, Dawson-Rose C. The Relationships Among Social Capital, HIV Self-Management, and Substance Use in Women. West J Nurs Res. 2020;42(1):4-13. https://doi, org/10.1177/0193945919842874.

30. Pentecost C, Taket A. Understanding exercise uptake and adherence for people with chronic conditions: a new model demonstrating the importance of exercise identity, benefits of attending and support. Health Educ Res. 2011;26(5):908-22. https://doi.org/10.1093/her/cyr052.

31. Trivedi RB, Bryson CL, Udris E, Au DH. The influence of informal caregivers on adherence in COPD patients. Ann Behav Med. 2012;44(1):66-72. https://doi.org/10.1007/s12160-012-9355-8.

32. Parker WM, Ferreira K, Vernon L, Cardone KE. The delicate balance of keeping it all together: Using social capital to manage multiple medications for patients on dialysis. Res Social Adm Pharm. 2017;13(4):738-45. https:// doi.org/10.1016/j.sapharm.2016.07.008.

33. Bandura A. Social foundations of thought and action: A social cognitive theory. NJ: Prentice-Hall; 1986.

34. Y Luo AH Chen ZH Wang. 2016. Effect of parental rearing styles on learning burnout of middle school students: The mediating role of selfconcept. Psychol Dev and Educ.32;(1):65-72.https://doi.org/10.16187/j. cnki.issn1001-4918.2016.01.09.

35. Anderson RM, Funnell MM. Patient empowerment: myths and misconceptions. Patient Educ Couns. 2010;79(3):277-82. https://doi.org/10. 1016/j.pec.2009.07.025.

36. Zhou C, Ji X, Tan J, Wu Y. Psychometric properties of the Chinese version of the Client Empowerment Scale in chronic patients. Springerplus. 2016;5(1):1636. https://doi.org/10.1186/s40064-016-3183-4.

37. Edwards M, Davies M, Edwards A. What are the external influences on information exchange and shared decision-making in healthcare consultations: a meta-synthesis of the literature. Patient Educ Couns. 2009;75(1):37-52. https://doi.org/10.1016/j.pec.2008.09.025.

38. Sak G, Rothenfluh F, Schulz PJ. Assessing the predictive power of psychological empowerment and health literacy for older patients' participation in health care: a cross-sectional population-based study. BMC Geriatr. 2017;17(1):59. https://doi.org/10.1186/s12877-017-0448-x.

39. Sürücü HA, Besen DB, Erbil EY. Empowerment and Social Support as Predictors of Self-Care Behaviors and Glycemic Control in Individuals With Type 2 Diabetes. Clin Nurs Res. 2018;27(4):395-413. https://doi.org/10. 1177/1054773816688940. 
40. Hernandez-Tejada MA, Campbell JA, Walker RJ, Smalls BL, Davis KS, Egede LE. Diabetes empowerment, medication adherence and self-care behaviors in adults with type 2 diabetes. Diabetes Technol Ther. 2012;14(7):6304. https://doi.org/10.1089/dia.2011.0287.

41. Yang S, Hsue C, Lou Q. Does patient empowerment predict self-care behavior and glycosylated hemoglobin in chinese patients with type 2 diabetes? Diabetes Technol Ther. 2015;17(5):343-8. https://doi.org/10. 1089/dia.2014.0345.

42. Londono AM, Schulz PJ. Influences of health literacy, judgment skills, and empowerment on asthma self-management practices. Patient Educ Couns. 2015;98(7):908-17. https://doi.org/10.1016/j.pec.2015.03.003.

43. Chow SC, Shao J, Wang H, Lokhnygina Y. Sample size calculations in clinical research (3rd ed.). Boca Raton: CRC Press; 2017.

44. Williams D. On and Off the 'Net: Scales for Social Capital in an Online Era. J Comput-Mediat Commun. 2006;11:593-628. https://doi.org/10.1111/j. 1083-6101.2006.00029.x.

45. Mikky IF. Development of the Client Empowerment Scale (CES). University of Connecticut, Storrs, 2006

46. Song YC, Lin CC. The development and testing of a new hemodialysi selfmanagement instrument (HD-SMI). Journal of Nursing and Healthcare Research. 2009;5:51-9 (https://www.researchgate.net/publication/28725 3656_The_development_and_testing_of_anew_hemodialysis_selfmanagement_instrument_HD-SMI).

47. Hayes AF. Introduction to mediation, moderation and conditional process analysis: A regression-based approach. 2nd ed. New York, NY: Guilford Press; 2018.

48. Atashpeikar S, Jalilazar T, Heidarzadeh M. Self-Care Ability in Hemodialysis Patients. J Caring Sci. 2012;1 (1):31-5. https://doi.org/10.5681/jcs.2012.005.

49. Keyvanara M, Afshari M, Dezfoulian E. The Relationship between Social Capital and Quality of Life among Patients Referring to Diabetes Centers in Isfahan. Iran J Diabetes Res. 2018;2018:9353858. https://doi.org/10. 1155/2018/9353858.

50. Koetsenruijter J, van Eikelenboom N, van Lieshout J, Vassilev I, Lionis C, Todorova E, Wensing M. Social support and self-management capabilities in diabetes patients: An international observational study. Patient Educ Couns. 2016;99(4):638-43. https://doi.org/10.1016/j.pec.2015.10.029.

51. Fang J, Wang JW, Li J, Li H, Shao C. The correlates of social capital and adherence to healthy lifestyle in patients with coronary heart disease. Patient Prefer Adherence. 2017;11:1701-7. https://doi.org/10.2147/ppa. S140787.

52. Wright K, Sparks L, Hair H. Health Communication in the 21st Century. Oxford: WileyBlackwell; 2008.

53. van Woerkum C, Bouwman L.' 'Getting things done': an everyday-life perspective towards bridging the gap between intentions and practices in health-related behavior. Health Promot Int. 2014;29(2):278-86. https:// doi.org/10.1093/heapro/das059.

54. Super S, Wagemakers MA, Picavet HS, Verkooijen KT, Koelen MA. Strengthening sense of coherence: opportunities for theory building in health promotion. Health Promot Int. 2016;31(4):869-78. https://doi.org/ 10.1093/heapro/dav071.

\section{Publisher's Note}

Springer Nature remains neutral with regard to jurisdictional claims in published maps and institutional affiliations.

Ready to submit your research? Choose BMC and benefit from:

- fast, convenient online submission

- thorough peer review by experienced researchers in your field

- rapid publication on acceptance

- support for research data, including large and complex data types

- gold Open Access which fosters wider collaboration and increased citations

- maximum visibility for your research: over $100 \mathrm{M}$ website views per year

At BMC, research is always in progress.

Learn more biomedcentral.com/submissions 